DOI: 10.12731/wsd-2018-3-162-179

УДК 614.2

\title{
АНАЛИЗ ФОРМИРОВАНИЯ ПОНЯТИЯ ЗДОРОВОГО ОБРАЗА ЖИЗНИ СРЕДИ УЧАЩЕЙСЯ МОЛОДЕЖИ И МОТИВАЦИИ К НЕМУ В КОНТЕКСТЕ ПРЕДСТОЯЩЕЙ ПРОФЕССИОНАЛЬНОЙ ДЕЯТЕЛЬНОСТИ
}

\author{
Федоткина С.А., Гридин М.Ю., Хугаева Э.В.
}

В последние годы, наравне с актуальной проблемой неблагоприятного демографического прогноза, а также с перспективой увеличения пенсионного возраста, тема здорового образа жизни становится все более актуальной.

Благодаря политике государства, в настоящее время, осуществляется реализачия межсекторального взаимодействиям по контролю и профилактике неинфекиионных заболеваний с иелью создания необходимых условий для ведения здорового образа жизни (ЗОЖ) населения.

Но, несмотря на активную политику государства, многие россияне, и в том числе и учашаяся молодежь, не имеют достаточной мотивачии $\kappa$ ведению здорового образа жизни.

В рамках реализации популяционной стратегии профилактики неинфекционных заболеваний, формирование мотивачии к ЗОЖ у учащейся молодежи проходит во время их обучения в ВУЗах. Медицинские ВУЗы характерны тем, что они готовят специалистов, которые будут осуществлять популяционную стратегию, в том числе собственным примером.

Предметом изучения нашего исследования является уровень знаний по понятию здорового образа жизни. В нашей работе, на примере студентов, курсантов и клинических ординаторов военно-медицинской академии имени С.М. Кирова, была изучена самооценка образа жизни учащейся молодежи и мотивации к нему.

С этой целью был проведен выборочный сочиологический опрос обучающихся по специально разработанной анкете.

В результате обработки данных проведенного опроса, нам удалось вылснить, что большая часть респондентов имеет низкий уровень самосохранительной культуры и считает свой образ жизни недостаточно 
здоровым, а также желала бы его изменить. Учитывая данное желание наших респондентов, мы предполагаем, что активизировать мотивацию $\kappa$ здоровому образу жизни можно в рамках некоторых дисииплин.

Ключевые слова: здоровый образ жизни; мотивачия; профилактика неинфекиионных заболеваний; студенты; курсанты; клинические ординаторы; трудоспособный возраст; популяционная стратегия; молодежь.

\section{THE ANALYSIS OF THE FORMATION OF THE CONCEPT OF HEALTHY LIFESTYLE AMONG YOUTH AND MOTIVATING HIM IN THE CONTEXT OF FUTURE PROFESSIONAL ACTIVITY}

\section{Fedotkina S.A., Gridin M.Yu., Khugaeva E.V.}

For today, along with the topical problem of adverse demographic forecast, and in connection with the prospect of the increase of retirement age, the issue of healthy lifestyle is becoming increasingly important.

Thanks to the state policy, there is currently cross-sectoral interaction implemented for the purposes of the control and prevention of non-communicable diseases in order to create the necessary conditions for the population's healthy lifestyle.

But despite the active policy of the state, many Russians, including students, do not have sufficient motivation to lead a healthy lifestyle.

One of the components of the population strategy for non-communicable diseases prevention is the development of motivation to healthy lifestyle among students during their years at educational institutions. The specifics of medical universities are that the students trained there are the people to implement the population strategy of the future, including by providing a role model of themselves.

The subject of our study is the level of knowledge on the healthy lifestyle concept. In our research, which was based on students, military students and medical residents of Military Medical Academy named after S.M. Kirov, we analyzed the formation of the concept of healthy lifestyle among students and the motivation to such lifestyle.

In order to study the level of knowledge on the formation of motivation for a healthy lifestyle, a sample sociological survey of students on a specially designed questionnaire was conducted. 
As a result of processing the data of the survey, we were able to find out that most of the respondents have a low level of self-preservation culture and considers their lifestyle is not healthy enough, and would like to change it. Taking into account this desire of our respondents, we assume that it is possible to activate motivation to a healthy lifestyle within some disciplines.

Keywords: healthy lifestyle; motivation; prevention of non-communicable diseases; students; military trainees; clinical residents; population strategy; youth.

\section{Введение}

Всемирная организация здравоохранения декларирует укрепление здоровья, формирование здорового образа жизни (ЗОЖ) и борьбу с вредными привычками как задачи первоочерёдной важности и предлагает определение здорового образа жизни как образа жизни, основанного на принципах нравственности, защищающей от неблагоприятных воздействий окружающей среды, позволяющей сохранить нравственное, психическое и физическое здоровье.

В Российской Федерации, несмотря на активную политику государства, многие граждане не имеют достаточной мотивации на укрепление здоровья $[1,2]$. Кроме этого, по данным Росстата, за последние 10 лет демографический прогноз для Российской Федерации остается неблагоприятным. Он складывается из наметившегося с 2016 г. динамики снижения рождаемости и сохранения высокого уровня смертности $[3,4]$.

О необходимости формировании здорового образа жизни у граждан, начиная с детского возраста, говорится в Федеральном законе N 323-Ф3 [5], которая обеспечивается путем проведения мероприятий, направленных на информирование граждан о факторах риска для их здоровья, формирование мотивации и создание условий к ведению здорового образа жизни, в том числе для занятий физической культурой и спортом $[6,26,27]$.

Формирование мотивации к ЗОЖ у учащейся молодежи проходит во время их обучения в ВУЗах [7-10], что в свою очередь является частью государственной политики по осуществлению межсекторального взаимодействия в рамках реализации популяционной стратегии профилактики неинфекционных заболеваний и формирование мотивации к ЗОЖ у учащейся молодежи [11, 12, 13, 22-25].

Основным принципом популяционной стратегии профилактики хронических неинфекционных заболеваний (ХНИЗ), является воздействие на специфику модифицированных факторов риска таких как курение, 
нездоровое питание, низкая физическая активность, избыточное потребление алкоголя, хроническое психоэмоциональное напряжение. [28, 29, $31,21,32,13]$.

В нашем исследовании образ жизни студенческой молодёжи нас интересует в контексте предстоящей их профессиональной деятельности. Формирование мотивации к здоровому и активному образу жизни населения - одна из главных общекультурных задач врачей и педагогов. В свою очередь, успешность профессиональной деятельности по созданию здоровьесберегающей среды зависит от состояния собственного физического и духовного здоровья [35-37], т.к предполагает значительную эмоциональную напряжённость и наличие факторов, способствующих развитию стресса и ХНИЗ $[33,19,34,13,23]$.

В медицинских ВУЗах, в том числе и в военно-медицинской академии им. С.М. Кирова, готовят специалистов, которые не только получают знания по основам формирования ЗОЖ, но и способных осуществлять популяционную стратегию в среднесрочной перспективе, в том числе собственным примером.

Однако, не смотря на предпринимаемые государственные меры [1417], как отмечают некоторые авторы [18-21], значительная часть учащейся молодежи трудоспособного возраста, в том числе будущие медицинские работники, не имеют достаточной мотивации к ведению здорового образа жизни.

С целью изучения уровня знаний по формированию мотивации здорового образа жизни, в военно-медицинской академии имени С.М. Кирова был проведен выборочный социологический опрос курсантов, студентов и клинических ординаторов.

\section{Материалы и методы}

Для достижения цели нашего исследования была разработана специальная анкета из 20 вопросов. Условно все вопросы можно разделить на четыре части, первая из которых была направлена на выяснения базовых знаний о собственном состоянии здоровья, вторая часть - на самооценку образа жизни, третья часть - на самооценку мотивации к ЗОЖ. Заключительные пять вопросов - это паспортная часть. В данной статье проанализированы обобщённые результаты двух вопросов из второй и третьей частей анкеты.

В исследовании в качестве респондентов принимали участие 152 человека. Из них курсантов - 59 человек $(38,8 \%)$ от общего числа опрошен- 
ных, из них (58 мужчин и 1 женщина); клинических ординаторов - 27 человек (17,7\%) из всех респондентов, из них (9 мужчин и 18 женщин); студентов - 66 человек $(43,4 \%)$ от общего числа опрошенных, из них (3 курс 24 человека - 7 мужчин и 17 женщин; 4 курс 42 человека - 17 мужчин и 25 женщин).

Средний возраст опрошенных составил 25 лет (у курсантов и студентов 21-22 года, у клинических ординаторов - 25-27 лет), т.е. являются потенциальными лицами трудоспособного возраста.

Структура выборки позволила выделить три группы респондентов: будущих военных врачей, будущих гражданских врачей и уже состоявшихся врачей. И тем интереснее оказались полученные нами результаты.

\section{Результаты и обсуждение}

При более или менее одинаковом уровне основных потребностей, характерном для общества, каждый человек отличается индивидуальным способом их удовлетворения. Хорошим навыком, который приобретает студенческая молодёжь в ВУЗах - это умение осознавать и анализировать своё поведение. Одним из главных компонентов проведенного нами исследования, явилась способность наших респондентов к критической оценке своего образа жизни.

В результате обработки данных, выяснилось, что респонденты способны критически оценить свой образ жизни, причем, большинство из них считает свой образ жизни не совсем здоровый $-62,5 \%$, причем, в равной степени, как мужчины, так и женщины. Среди курсантов такой ответ выбрали 57,6\%, среди клинических ординаторов 52\%, а среди студентов $-71 \%$. В свою очередь, такая значительная доля респондентов, не считающих свой образ жизни здоровым, может косвенно свидетельствовать о недостаточной мотивации к нему (Рис.1). Вероятней всего, уровень влияния воспитательных элементов образовательного процесса на формирование у обучающихся устойчивой мотивации к здоровому образу жизни, недостаточен.

Значительная часть респондентов (16\%) отметила, что их образ жизни далек от здорового. Наиболее многочисленной группой, выбравшей такой ответ оказалась среди клинических ординаторов - 29,6\%. Среди курсантов на этот вопрос положительно ответили $8,5 \%$, среди студентов $-10,6 \%$ соответственно. Это может свидетельствовать о том, что жизненный опыт и уровень образования клинических ординаторов позволяют дать более критическую оценку своему образу жизни. 


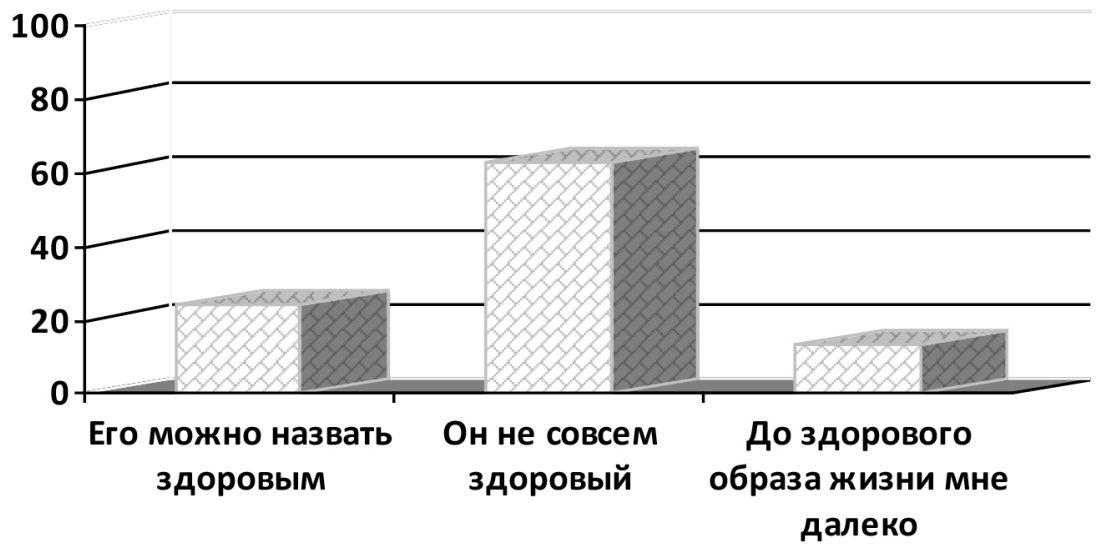

Рис. 1. Характеристика самооценки образа жизни курсантов, студентов, клинических ординаторов

Нас интересовала не только оценка фактического состояния образа жизни респондентов и умение его оценить, но также и понимание респондентами того, что они сами могут предпринять для того, чтобы приблизить свой образ жизни к здоровому (Табл. 1).

Таблий 1.

Характеристика мнений респондентов о способах приближения к здоровому образу жизни

\begin{tabular}{|c|c|c|c|c|c|c|}
\hline \multirow{3}{*}{ Показатель } & \multicolumn{6}{|c|}{ Респонденты } \\
\hline & \multicolumn{4}{|c|}{ По структуре выборки } & \multicolumn{2}{|c|}{$\begin{array}{c}\text { По гендерному } \\
\text { признаку }\end{array}$} \\
\hline & $\begin{array}{c}\text { Курсан- } \\
\text { ты (\%) }\end{array}$ & $\begin{array}{c}\text { Орди- } \\
\text { наторы } \\
(\%)\end{array}$ & $\begin{array}{c}\text { Студен- } \\
\text { ты (\%) }\end{array}$ & $\begin{array}{c}\text { Итог } \\
\text { (\%) }\end{array}$ & $\begin{array}{c}\text { Муж- } \\
\text { чины } \\
(\%)\end{array}$ & $\begin{array}{c}\text { Жен- } \\
\text { щины } \\
(\%)\end{array}$ \\
\hline \multicolumn{7}{|c|}{ 1. Снизить употребление алкоголя. } \\
\hline Да & 39,0 & 59,3 & 57,5 & 50,7 & 44,4 & 59,7 \\
\hline Нет & 6,8 & 3,7 & 6,1 & 5,9 & 6,7 & 4,8 \\
\hline $\begin{array}{c}\text { Это не наносит ущерба } \\
\text { моему здоровью }\end{array}$ & 54,2 & 37,0 & 36,4 & 43,4 & 48,9 & 35,5 \\
\hline Итог & 100,0 & 100,0 & 100,0 & 100,0 & 100,0 & 100,0 \\
\hline \multicolumn{7}{|c|}{ 2. Снизить число выкуриваемых сигарет. } \\
\hline Да & 61,0 & 59,3 & 57,6 & 59,2 & 58,9 & 59,7 \\
\hline
\end{tabular}


Окончание табл. 1.

\begin{tabular}{|c|c|c|c|c|c|c|}
\hline Нет & 6,8 & 7,4 & 3,0 & 5,3 & 6,7 & 3,2 \\
\hline $\begin{array}{c}\text { Это не наносит ущерба } \\
\text { моему здоровью }\end{array}$ & 32,2 & 33,3 & 39,4 & 35,5 & 34,4 & 37,1 \\
\hline Итог & 100,0 & 100,0 & 100,0 & 100,0 & 100,0 & 100,0 \\
\hline \multicolumn{7}{|c|}{ 3. Уменьшить потребление соли, сахара, мучного. } \\
\hline Да & 52,6 & 66,7 & 77,3 & 65,8 & 56,7 & 79,1 \\
\hline Нет & 22,0 & 7,4 & 7,6 & 13,1 & 18,9 & 4,8 \\
\hline $\begin{array}{c}\text { Это не наносит ущерба } \\
\text { моему здоровью }\end{array}$ & 25,4 & 25,9 & 15,1 & 21,1 & 24,4 & 16,1 \\
\hline Итог & 100,0 & 100,0 & 100,0 & 100,0 & 100,0 & 100,0 \\
\hline \multicolumn{7}{|c|}{ 4. Сделать свой отдых более здоровым. } \\
\hline Да & 88,1 & 96,3 & 83,3 & 87,5 & 85,6 & 90,3 \\
\hline Нет & 1,7 & 0,0 & 3,0 & 2,0 & 1,1 & 3,2 \\
\hline $\begin{array}{c}\text { Это не наносит ущерба } \\
\text { моему здоровью }\end{array}$ & 10,2 & 3,7 & 13,7 & 10,5 & 13,3 & 6,5 \\
\hline Итог & 100,0 & 100,0 & 100,0 & 100,0 & 100,0 & 100,0 \\
\hline
\end{tabular}

Мнения опрошенных относительно уменьшения употребления алкоголя разделились: 50,7\% всех опрошенных считает, что этот шаг приблизит их образ жизни к здоровому, а 43,4\% считают, что употребление алкоголя не наносит ущерба их здоровью.

Удивительным оказался тот факт, что подавляющее большинство опрошенных - курящие в той или иной степени - 94,7\%. При этом, большая часть из них считает, что уменьшение числа выкуриваемых сигарет так же способствует приближению их образа жизни к здоровому - 59,2\%.

С утверждением того, что изменение пищевого поведения, а именно уменьшение потребления соли, сахара и мучного положительно скажется на их образе жизни, согласны $65,8 \%$ респондентов. Причём женщин, которые придерживаются такого мнения на 22,2\% больше, чем мужчин.

Интересным оказался тот факт, что 87,5\% без значительных гендерных различий из числа опрошенных уверены в том, что, если сделать своей отдых более здоровым, это будет способствовать оздоровлению их образа жизни. Приблизительно одинаково в этом уверены 85,6\% мужчин и 90,3\% женщин. А вот среди исследуемых групп нами замечены различия. Подавляющее большинство - 96,3\% таких респондентов выявлено в группе клинических ординаторов, $88,1 \%$ - среди курсантов и $83,3 \%$ среди студентов.

Такой разброс ответов говорит о том, что у наших респондентов отсутствует целостная картина знаний о здоровом образе жизни, каким образом 
к нему можно приблизиться и на что они готовы ради этого. Однако все категории респондентов склоняются к мнению, что предложенные варианты ответов однозначно положительно отразятся на том образе жизни, который они ведут в настоящее время.

Из всех предложенных респондентам вариантов ответов, самым значимым способом приближения их образа жизни к здоровому они выделили свой отдых.

Изменение пищевого поведения (снизить потребление соли, сахара, мучного) - это второй по значимости приоритет приближения образа жизни к здоровому у наших респондентов. Причем, женщинам этот способ отмечается как гораздо более приемлемый, чем мужчинам $(79,1 \%$ и 56,7\% соответственно).

Самым незначительным способом респонденты признали способ снизить употребление алкоголя (50,7\% от общего числа опрошенных), причем, наиболее высокий процент курсантов $(54,2 \%)$ считает, что употребление алкоголя не наносит ущерба их здоровью и они не готовы снизить его потребление.

\section{Заключение}

В военно-медицинской академии им. С.М. Кирова, готовят специалистов, которые наряду с общемедицинскими знаниями совершенствуют свой процесс формирования устойчивой мотивации к здоровому образу жизни.

В качестве респондентов в нашем исследовании приняли участие курсанты и студенты четвёртого курса, а также клинические ординаторы 1-го года обучения. В данной статье проанализированы обобщённые результаты двух из 20 вопросов анкеты, направленных на изучение самооценки образа жизни и мотивации к ЗОЖ.

В результате обработки данных опроса в части формирования устойчивой мотивации к ЗОЖ, нам удалось выяснить, что опрошенные нами курсанты, клинические ординаторы и студенты способны критически оценить свой образ жизни, а большая часть из них считает его не совсем здоровым. Наиболее приемлемым способом приближения своего образа жизни к здоровому наши респонденты считают оптимизацию своего отдыха как в режиме рабочего дня, так и вовремя отпуска.

После обработки полученных данных о приоритетных способах приближения своего образа жизни к здоровому, мы пришли к выводам, что значительная часть опрошенной нами учащейся молодежи имеет низкий 
уровень самосохранительной культуры и имеет некоторые базовые понятия о здоровом образе жизни. Однако, объем этих знаний, к сожалению, минимален, и требует серьезного углубления и конкретизации.

Желание наших респондентов изменить свой образ жизни к более здоровому, можно использовать в учебном процессе внесением изменений в структуру проведения занятий дисциплин «Организация общественного здоровья здравоохранение», гигиена и др., в части формирования навыков проведения профилактических занятий в Школах Здоровья.

Это в свою очередь, может способствовать усилению мотивации к здоровому образу жизни самих респондентов, пригодится им в клинической практике и поможет осуществлять профилактику неинфекционных заболеваний среди населения. Медицинские специалисты, мотивированные на ЗОЖ способны эффективно осуществлять популяционную стратегию.

\section{Список литературы}

1. Воробьева И.Н. Здоровый образ жизни как индикатор для определения базового стиля жизни // Материалы межвузовского сборника научных работ VIII Всероссийской научно-практической конференции «Проблемы фундаментальной подготовки в школе и вузе в контексте современности». 2017. C. 301-303.

2. Федоткина С.А., Яцковская Л.Н. Готовность к изменению образа жизни среди студентов и учащихся колледжей // Современные исследования социальных проблем. 2012. №3. С. 9-12.

3. Бойцов С.А., Вылегжанин С.В., Гилева Ф.А., Гулин А.Н., Ипатов П.В., Калинина А.М., Линчак Р.М., Пономарева Е.Г. Совершенствование профилактики хронических неинфекционных заболеваний в учреждениях здравоохранения // Профилактическая Медицина. 2013. № 2. С. 3-12.

4. Российский статистический ежегодник. 2017: Стат.сб. / Росстат. Р76 М. 2017. 686 c.

5. Федеральный закон Российской Федерации от 21.11.2011 г. № 323-Ф3 «Об основах охраны здоровья граждан РФ». М. 2011. 56 с.

6. Меньшов И.В. Спортивный клуб в образовательной организации СПО: новые возможности формирования здорового образа жизни студентов. // VI Международная научно-практическая конференция «Экология, здоровье, спорт». Чита. 2015. С. 321-326.

7. Федоткина С.А., Иванова А.А., Яковлева Т.В. Здоровьесберегающая деятельность в образовательных и высших учебных заведениях России // Вестник РГМУ. 2012. № 3. С. 68-71. 
8. Васюкова Т.П., Панская М.А. Здоровьеформирующие и здоровьесберегающие технологии в учебно-воспитательном процессе // Мат. всеросс. науч.-практич. конференц. «Актуальные проблемы и перспективы теории и практики физической культуры, спорта, туризма и двигательной рекреации в современном мире». 2016. С. 112-117.

9. Барханская Е.В. Роль здоровьесберегающих технологий в современном образовании // Актуальные проблемы гуманитарных и естественных наук. 2013. № 10 (2). С. 147-149.

10. Кадирова Н.С. Сулейманова Р.М., Эбулисова Р.М. Студенты-медики: отношение к здоровому образу жизни // Мат. всеросс. конф. М.: МедиАль. 2017. № 1 (19). С. 422-423.

11. Дэбэева Т.Б. Влияние социальной рекламы на процесс формирования здорового образа жизни молодежи // VI Международная научно-практическая конференция «Экология, здоровье, спорт». Чита 2015. С. 107-113.

12. Приказ Министерства здравоохранения Российской Федерации от 30.09.2015 г. N 683н «Об утверждении порядка организации и осуществления профилактики неинфекционных заболеваний и проведения мероприятий по формированию здорового образа жизни в медицинских организациях». М. 2015. 6 с.

13. Эмберсон Д., Уинкан П., Моррис Р. Популяционная стратегия // РМЖ. 2013. № 20 C. 13-20.

14. Долженков Е.А., Егорычева Е.В., Чернышёва И.В., Мустафина Д.А. Влияние сна на физическую подготовку студента. // Международный студенческий вестник. 2015. № 5-4. С. 493-494.

15. Всемирный атлас профилактики сердечно-сосудистых заболеваний и борьбы с ними / Под ред.: Mendis S., Puska P., Norrving В. ВОЗ. Женева. 2013. С. 155.

16. Модестов А.А., Косова С.А., Иванова А.А, Федоткина С.А. Здоровьесберегающее поведение подростков и молодежи как основа здоровья будущих родителей // Российский педиатрический журнал. 2012. № 3. С. 46-50.

17. Любаев А.В. Влияние физических упражнений на умственную деятельность студентов и их взаимосвязь. // Молодой ученный. 2015. № 18 (98). C. $423-425$.

18. Архипова Т. В., Эшиев А. К. Здоровый образ жизни как компетентность. // VI Международная научно-практическая конференция «Экология, здоровье, спорт». Чита 2015. С 64-71.

19. Стратегия странового сотрудничества Всемирной организации здравоохранения и Министерства здравоохранения Российской Федерации на 2014-2020 годы. Копенгаген: Всемирная организация здравоохранения. 2014. С. 53. 
20. Яцковская Л.Н. Самооценка молодыми людьми своего образа жизни и готовность его изменить. // Мат. V Всероссийск. с междунар. участ. науч.-практич. конф. «Здоровье населения - основа процветания России». Анапа. 2011. С. 374-375.

21. Коченко Э.В., Астрейко Н.Н. Актуальные проблемы образа жизни молодёжи и пути их решения // Сборник научных статей по материалам I Республиканской научно-практической конференции с международным участием. Минск. 2017. С. 266-269.

22. Bolbrinker J., Zaidi Touis L., Gohlke H., Weisser B., Kreutz R. European guidelines on lifestyle changes for management of hypertension: Awareness and implementation of recommendations among German and European physicians. Herz. 2017 May 22. doi: 10.1007/s00059-017-4575-0.

23. European Detailed Mortality Database. URL: http://data.euro.who.int/dmdb/ (Дата обращения 15 мая 2018).

24. D. Mozaffarian et al., "Global Sodium Consumption and Death from Cardiovascular Causes,” N. Engl. J. Med., vol. 371, no. 7, pp. 624-634, Aug. 2014.

25 Lerssrimongkol C., Wisetborisut A., Angkurawaranon C. et al. Active commuting and cardiovascular risk among health care workers. Occup Med (Lond). 2016 Aug. 66(6):483-7.

26 Artyukhov I.P., Grinshtein Y.I., Petrova M.M. et al. Prevalence of arterial hypertension in the Krasnoyarsk Krai (Siberia, Russia). BMC Cardiovascular Disorders (2017) 17:138.

27 E. Nagele et al., "Clinical effectiveness of stress-reduction techniques in patients with hypertension,” J. Hypertens., vol. 32, no. 10, pp. 1936-1944, Oct. 2014.

28 Федоткина С.А., Хугаева Э.В. К вопросу о применении и популяционной стратегии для лиц трудоспособного возраста в рамках первичной медико-санитарной помощи. // Материалы Российской научно-практической конференции «Современные научные и образовательные стратегии в общественном здоровье». Санкт-Петербург 2018. С. 228-235.

29 Хугаева Э.В. Анализ основных показателей здоровья лиц трудоспособного возраста от болезней системы кровообращения в результате использования популяционной стратегии // Сборник научных трудов по итогам конференции «Актуальные проблемы медицины в России и за рубежом». Новосибирск. 2018. С. 52-56.

30 Хугаева Э.В. Оценка эффективности снижения табакокурения среди молодежи на примере обучающихся г. Санкт-Петербург. // Ежемесячный международный научный журнал «International science project». 2018. C. 5-11. 
31 Федоткина С.А. Комплексное социально-гигиенические исследование самосохранительного поведения и здоровья молодежи России: дис. д-ра. мед. наук. М.,: 2014 г. 292 с.

32 Ушаков А.В., Иванченко В.С., Гагарина А.А. Особенности суточного профиля артериального давления и вариабельности сердечного ритма у больных артериальной гипертензией в зависимости от уровня физической активности и психоэмоционального напряжения. // Российский кардиологический журнал. 2017. 4 (144). С. 23-28.

33 Кулганов В.А. Психоэмоциональное напряжение и утомление учителя: механизмы, диагностика и профилактика. // Журнал Известия Российского государственного педагогического университета им. А. И. Герцена. 2009. №100. C. 131-142.

34 Кришталь Т.Ю., Моисеева И.Е. Первичная профилактика сердечно-сосудистых заболеваний в общей врачебной практике // Российский семейный врач. 2015. № 4. С. 4-19.

35 Руденко Е. А. Педагогические ценности учителя начальных классов // Начальная школа плюс до и после. 2004. № 12. С. 16-18. http://school2100. com/upload/iblock/3ca/3cad128e52cb81ba3eae7801b8931859.pdf

36 Короткова М.О., Павлова Е.Ю., Насыбулина Г.М. Образ жизни учителей и их роль в гигиеническом воспитании учащихся. // Журнал Профилактика заболеваний и укрепление здоровья. 2007. № 4(10). С. 27-30.

37 Кенебас А.Г., Щербинина И.А. Личный пример семьи и педагога как метод формирования здорового образа жизни среди студентов. Здоровьесберегающие технологии в современном образовании. Сборник материалов II Всероссийской научно-практической конференции с международным участием. 2017. С. 42-45.

\section{References}

1. Vorobieva I.N. Zdorovyy obraz zhizni kak indikator dlya opredeleniya bazovogo stilya zhizni [Healthy Lifestyle as an Indicator to Determine the Basic Lifestyle]. Materialy mezhvuzovskogo sbornika nauchnykh rabot VIII Vserossiyskoy nauchno-prakticheskoy konferentsii «Problemy fundamental'noy podgotovki $v$ shkole $i$ vuze v kontekste sovremen-nosti» [Materials of Inter-University Collection of Research Papers of the VIII All-Russian Applied Research Conference "Problems of Fundamental Education at School and University from the Perspective of Today's World"]. 2017, pp. 301-303.

2. Fedotkina S.A., Yatskovskaya L.N. Gotovnost' k izmeneniyu obraza zhizni sredi studentov i uchashchikhsya kolledzhey [Readiness to Change Lifestyle among 
University Students and Vocational Education Institutions Students]. Sovremennyie Issledovaniya Sotsialnykh Problem [Modern Research of Social Problems]. 2012. No. 3, pp. 9-12.

3. Boytsov S.A., Vylegzhanin V.S., Gileva F.A., Gulin A.N., Ipatov P.V., Kalinina A.M., Linchak R.M., Ponomareva E.G. Sovershenstvovanie profilaktiki khronicheskikh neinfektsionnykh zabolevaniy v uchrezhdeniyakh zdravookhraneniya [Improving the prevention of chronic reinfection diseases in health care]. Profilakticheskaya Meditsina [Preventive Medicine]. 2013. No. 2, pp. 3-12.

4. Rossiyskiy statisticheskiy ezhegodnik [Russian statistical yearbook]. Official publication of Rosstat. 2017. Russtat. P76 M. 2017. 686 p.

5. Federal'nyy zakon Rossiyskoy Federatsii ot 21.11.2011 g. № 323-FZ «Ob osnovakh okhrany zdorov'ya grazhdan $R F$ » [Federal Law of the Russian Federation dated 21.11.2011 No. 323-Ф3 "On Basics of Health Protection of the Citizens in the Russian Federation"]. M. 2011. 56 p.

6. Menshov I.V. Sportivnyy klub v obrazovatel'noy organizatsii SPO: novye vozmozhnosti formirovaniya zdorovogo obraza zhizni studentov [Sports club in educational organization of SPO: new opportunities of formation of a healthy lifestyle of students]. VI Mezhdunarodnaya nauchno-prakticheskaya konferentsiya «Ekologiya, zdorov'e, sport» [VI international scientific and practical conference "Ecology, health, sport"]. Chita. 2015, pp. 321-326.

7. Fedotkina S.A., Ivanova A.A., Yakovleva T.V. Zdorov'esberegayushchaya deyatel'nost' v obrazovatel'nykh i vysshikh uchebnykh zavedeniyakh Rossii Health Saving Activities in Educational and Higher Education Institutions of Russia]. Vestnik RGMU [Bulletin of RNMU]. 2012. No. 3, pp. 68-71.

8. Vasyukova T.P., Panskaya M.A. Zdorov'eformiruyushchie i zdoro-v'esberegayushchie tekhnologii $v$ uchebno-vospitatel'nom protsesse [Health-forming and Health-Preserving Technologies in the Educational Process]. Mat. vseross. nauch.-praktich. konferents. "Aktual'nye problemy i perspektivy teorii i praktiki fizicheskoy kul'tury, sporta, turizma i dvigatel'noy rekreatsii v sovremennom mire» [Materials of All-Russian Applied Research Conference "Actual Problems and Prospects of Theory and Practice of Physical Education, Sport, Tourism and Active Recreation in the Modern World"]. 2016, pp. 112-117.

9. Barkhanskaya E.V. Rol' zdorov'esberegayushchikh tekhnologiy v sovremen-nom obrazovanii [The Role of Health Saving Technologies in Modern Education]. Aktual'nye problemy gumanitarnykh i estestvennykh nauk [Actual Problems of Humanitarian and Natural Sciences]. 2013. No. 10(2), pp. 147-149.

10. Kadirova N.S., Suleymanova R.M., Ebulisova R.M. Studenty-mediki: otnoshenie k zdorovomu obrazu zhizni [Medical Students: Attitude towards Healthy 
Lifestyle]. Mat. vseross. konf. [Materials of the All-Russian Conference]. M. MediAl. 2017. No. 1 (19), pp. 422-423.

11. Debeeva T.B. Vliyanie sotsial'noy reklamy na protsess formi-rovaniya zdorovogo obraza zhizni molodezhi [The Influence of Social Advertising on the Healthy Lifestyle Development among Young People]. VI Mezhdunarodnaya nauchno-prakticheskaya konferentsiya «Ekologiya, zdorov'e, sport» [VI International Applied Research Conference "Environment, Health, Sport"]. Chita, 2015, pp. 107-113.

12. Prikaz Ministerstva zdravookhraneniya Rossiyskoy Federa-tsii ot 30.09.2015 g. $N 683 n$ "Ob utverzhdenii poryadka organizatsii i osushchestvleniya profilaktiki neinfektsionnykh zabolevaniy i provedeniya meropriyatiy po formirovaniyu zdorovogo obraza zhizni v meditsinskikh organizatsiyakh» [Order No. 683n 30.09.2015 "On the Approval of the Procedure of Organization and Implementation of Non-communicable Diseases Prevention and the Measures to Promote Healthy Lifestyle in Medical Organizations"]. V. 2015. 6 p.

13. Amberson D., Wincan P., Morris R. Populyatsionnaya strategiya [Population-Based Strategy]. $R M J$ [Breast cancer]. 2013. No. 20, pp. 13-20.

14. Dolzhenkov E.A., Egorycheva E.V., Chernysheva I.V., Mustafina D.A. Vliyanie sna na fizicheskuyu podgotovku studenta [The effect of sleep on the physical training of the student]. Mezhdunarodny Studentchesky Vestnik [International Student Journal]. 2015. No. 5-4, pp. 493-494.

15. Vsemirnyy atlas profilaktiki serdechno-sosudistykh zabole-vaniy i bor 'by s nimi [The world Atlas of cardiovascular disease prevention and control] (EDS.): Mendis s., Puska p., Norrving, who. Geneva. 2013. P. 155.

16. Modestov A.A., Kosova S.A., Ivanova A.A., Fedotkina S.A. Zdorov'esberegayushchee povedenie podrostkov i molodezhi kak osnova zdorov'ya budushchikh roditeley [Health saving behavior of adolescents and young people as the basis of the health of future parents]. Rossiysky Pediatrichesky Zhurnal [Russian Pediatric Journal]. 2012. No. 3, pp. 46-50.

17. Liubaev A.V. Vliyanie fizicheskikh uprazhneniy na umstvennuyu deyatel'nost' studentov i ikh vzaimosvyaz' [The Influence of Physical Exercise on the Mental Activity of Students and the Correlation of these Characteristics]. Molodoy Ucheny [Young Scientist] 2015. No. 18 (98), pp. 423-425.

18. Arkhipova T.V., Eshiev A.K. Zdorovyy obraz zhizni kak kompetentnost [Healthy Lifestyle as a Competence]. VI Mezhdunarodnaya nauchno-prakticheskaya konferentsiya "Ekologiya, zdorov'e, sport» [VI International Applied Research Conference "Environment, Health, Sport"]. Chita. 2015, pp. 64-71.

19. Strategiya stranovogo sotrudnichestva Vsemirnoy organizatsii zdravookhraneniya i Ministerstva zdravookhraneniya Rossiyskoy Federatsii na 2014-2020 gody 
[Country cooperation strategy of the world health organization and the Ministry of health of the Russian Federation for 2014-2020]. Copenhagen: world health organization. 2014. P. 53.

20. Yatskovskaya L.N. Samootsenka molodymi lyud'mi svoego obraza zhizni i gotovnost' ego izmenit' [Self-esteem by young people of their way of life and their readiness to change]. Mat. V Vserossiysk. s mezhdunar. uchast. nauch-praktich. konf. «Zdorov'e naseleniya - osnova protsvetaniya Rossii» [Materials V Russian. with intern. participants. scientific-practical. Conf. "Public health is the basis of Russia's prosperity"]. Anapa. 2011, pp. 374-375.

21. Kochenko E.V., Astreyko N.N. Aktual'nye problemy obraza zhizni molodezhi i puti ikh resheniya [Topical Problems of the Lifestyle of the Youth and the Ways towards the Solution of these Problems]. Sbornik nauchnykh statey po materialam I Respublikanskoy nauchno-prakticheskoy konferentsii s mezhdunarod-nym uchastiem [Proceedings of I Republican Applied Research Conference with International Participation]. Minsk 2017, pp. 266-269.

22. Bolbrinker J., Zaidi Touis L., Gohlke H., Weisser B., Kreutz R. European guidelines on lifestyle changes for management of hypertension: Awareness and implementation of recommendations among German and European physicians. Herz. 2017.

23. European Detailed Mortality Database. http://data.euro.who.int/dmdb/

24. D. Mozaffarian et al., "Global Sodium Consumption and Death from Cardiovascular Causes," N. Engl. J. Med., vol. 371, no. 7, pp. 624-634. 2014.

25. Lerssrimongkol C., Wisetborisut A., Angkurawaranon C. et al. Active commuting and cardiovascular risk among health care workers. Occup Med (Lond). 2016 Aug. 66(6):483-7.

26. Artyukhov I.P., Grinshtein Y.I., Petrova M.M. et al. Prevalence of arterial hypertension in the Krasnoyarsk Krai (Siberia, Russia). BMC Cardiovascular Disorders (2017) 17:138.

27. E. Nagele et al., "Clinical effectiveness of stress-reduction techniques in patients with hypertension," J. Hypertens., vol. 32, no. 10, pp. 1936-1944. 2014.

28. Fedotkina S.A., Khugaeva E.V. K voprosu o primenenii i populyatsi-onnoy strategii dlya lits trudosposobnogo vozrasta $v$ ramkakh pervichnoy mediko-sanitarnoy pomoshchi [To the question of the application and population-based strategy for people of working age in the framework of primary health care]. $M a-$ terialy Rossiyskoy nauchno-prakticheskoy konferentsii "Sovremennye nauchnye i obrazovatel'nye strategii v obshchestvennom zdorov'e» [Materials of the Russian scientific-practical conference "Modern scientific and educational strategies in public health"]. St. Petersburg 2018, pp. 228-235. 
29 Khugaeva E.V. Analiz osnovnykh pokazateley zdorov'ya lits trudospo-sobnogo vozrasta ot bolezney sistemy krovoobrashcheniya $\mathrm{v}$ rezul'tate is-pol'zovaniya populyatsionnoy strategii [Analysis of the main indicators of health of persons of working age from diseases of the circulatory system as a result of the use of population strategy]. Sbornik nauchnykh trudov po ito-gam konferentsii «Aktual'nye problemy meditsiny $v$ Rossii $i$ za rubezhom» [Collection of scientific papers on the results of the conference "Actual problems of medicine in Russia and abroad"]. Novosibirsk. 2018, pp. 52-56.

30 Khugaeva E.V. Otsenka effektivnosti snizheniya tabakokureniya sredi molodezhi na primere obuchayushchikhsya g. Sankt-Peterburg [Evaluation of the effectiveness of reducing tobacco smoking among young people on the example of students in St. Petersburg]. Ezhemesyachnyy mezhdunarodnyy nauchnyy zhurnal «International science project» [Monthly international scientific journal "International science project"]. 2018, pp. 5-11.

31 Fedotkin S.A. Kompleksnoe sotsial'no-gigienicheskie issledovanie samosokhranitel'nogo povedeniya i zdorov'ya molodezhi Rossii [Complex social-hygienic research of health behaviour and health of the youth of Russia]: dis. Dr. honey. sciences'. M.,: 2014292 p.

32. Ushakov A.V., Ivanchenko V.S., Gagarina A.A. Osobennosti sutochnogo profilya arterial'nogo davleniya i variabel'nosti serdechnogo ritma u bol'nykh arterial'noy gipertenziey $\mathrm{v}$ zavisimosti ot urovnya fizicheskoy aktivnosti i psikhoemotsional'nogo napryazheniya [Features of the daily profile of blood pressure and heart rate variability in patients with hypertension, depending on the level of physical activity and psychoemotional stress]. Rossiyskiy kardiologicheskiy zhurnal [Russian journal of cardiology]. 2017. 4 (144), pp. 23-28.

33. Kurganov V.A. Psikhoemotsional'noe napryazhenie i utomlenie uchi-telya: mekhanizmy, diagnostika i profilaktika [Psychoemotional tension and fatigue teachers: mechanisms, diagnosis and prevention]. Zhurnal Izvestiya Rossiy-skogo gosudarstvennogo pedagogicheskogo universiteta im. A.I. Gertsena [Journal of news of the Russian state pedagogical University]. 2009. No. 100, pp. 131-142.

34. Krishtal T.Yu., Moiseeva I.E. Pervichnaya profilaktika serdechno-sosudistykh zabolevaniy v obshchey vrachebnoy praktike [Primary prevention of cardiovascular diseases in General medical practice]. Rossiyskiy semeynyy vrach [Russian family doctor]. 2015. No. 4, pp. 4-19.

35. Rudenko E. Nachal'naya shkola plyus do i posle [Elementary school plus before and after]. 2004. No. 12, pp. 16-18. http://school2100.com/upload/iblock/3ca/ 3 cad128e52cb81ba3eae7801b8931859.pdf 
36. Korotkova M.O., Pavlova E.Yu., Nasybulina G.M. Obraz zhizni uchiteley i ikh rol' $v$ gigienicheskom vospitanii uchashchikhsya [The way of life of teachers and their role in the hygienic education of students]. Zhurnal Profi-laktika zabolevaniy i ukreplenie zdorov'ya [Journal of disease Prevention and health promotion]. 2007. № 4 (10), pp. 27-30.

37. Kenebas A.G., Shcherbinina I.A. Lichnyy primer sem'i i pedagoga kak metod formirovaniya zdorovogo obraza zhizni sredi studentov. Zdoro-v'esberegayushchie tekhnologii v sovremennom obrazovanii [Personal example of the family and of the teacher as a method of formation of healthy lifestyle among students. Health-saving technologies in modern education]. Sbornik materialov II Vserossiyskoy nauchno-prakticheskoy konferentsii s mezhdunarodnym uchastiem [Collection of materials of the II all-Russian scientific-practical conference with international participation]. 2017, pp. 42-45.

\section{ДАННЫЕ ОБ АВТОРАХ}

Федоткина Светлана Александровна, доктор медицинских наук, доцент кафедры общественного здоровья и экономики военного здравоохранения

Федеральное государственное бюджетное военное образовательное учреждение высшего образования Военно-медицинской академии им. С.М. Кирова; Федеральное государственное бюджетное образовательное учреждение высшего образования «Санкт-Петербургский государственный университет», Медииинский колледж

ул. Академика Лебедева, 6, г. Санкт-Петербург, 194044, Российская Федеращия; линия Менделеевская, 5, г. Санкт-Петербург, 199034, Российская Федерачия

safedotkina@mail.ru

Гридин Михаил Юрьевич, преподаватель

Федеральное государственное казенное военное образовательное учреждение высшего образования "Краснодарское высшее военное авиаиионное училище летчиков имени героя Советского Союза А.К. Серова» Министерства обороны Российской Федерации ул. Дзержинского, 135, г. Краснодар, Российская Федерачия ms.uavb.maykop@mail.ru

Хугаева Эльза Валерьевна, аспирант кафедры общественного здоровья и экономики военного здравоохранения 
Федеральное государственное бюджетное военное образовательное учреждение высшего образования Военно-медицинской академии им. С.М. Кирова

ул. Академика Лебедева, 6, г. Санкт-Петербург, 194044, Российская Федерация

hugaeva_elza@mail.ru

\section{DATA ABOUT THE AUTHORS}

Fedotkina Svetlana Aleksandrovna, Doctor of Medical Sciences, Associate Professor of the Department of Public Health and Economics of Military Health Care

Military medical Academy; Saint-Petersburg State University, Medical College

6, Lebedev Str., St.-Petersburg, 194044, Russian Federation; 5, Mendeleevskaya Line, Saint-Petersburg, 199034, Russian Federation safedotkina@mail.ru

SPIN-code: 1867-5544

Gridin Mikhail Yuryevich, Teacher

Krasnodar Higher Military Aviation School for Pilots named after the Hero of the Soviet Union A.K. Serov

135, Dzerzhinsky Str., Krasnodar, Russian Federation

ms.uavb.maykop@mail.ru

SPIN-code: 4331-3751

Khugaeva Elsa Valerevna, Postgraduate Student of the Department of public health and Economics of military health care Military medical Academy 6, Lebedev Str., St.-Petersburg, 194044, Russian Federation hugaeva_elza@mail.ru SPIN-code: 2728-1193 